\title{
Effects of Different Compound Treatments on Cold Resistance of Pitaya Plants
}

\author{
Qian Luo ${ }^{1}$, Tingting Wang ${ }^{1}$, Lanlei Wu ${ }^{1}$, Jirui Zhang ${ }^{1}$, Gong Yan, and Xian Luo ${ }^{1 *}$ \\ ${ }^{1}$ College of Horticulture, Sichuan Agricultural University, Chengdu, Sichuan, China
}

\begin{abstract}
In this study, using red pulp pitaya plants variety 'Taiwan No. 6' as experiment material, 2,4-epitheloside (BR), betaine (GB), calcium chloride $\left(\mathrm{CaCl}_{2}\right)$ and salicylic acid (SA) were selected as experimental factors which were set at three levels. The effects of different treatments on the cell membrane stability and osmotic adjustment substances of pitaya plants were studied by orthogonal design. The results showed that salicylic acid was the main factor affecting the relative conductivity and soluble sugar content. 2,4-epibrassinolide was the main factor affecting the content of malondialdehyde and free proline. $\mathrm{CaCl}_{2}$ was the main factor affecting the soluble protein content. The best concentration combination for improving the cold resistance of pitaya plants was as follows: BR $1 \mu \mathrm{g} / \mathrm{L}, \mathrm{GB} 2.5 \mathrm{mmol} / \mathrm{L}$, $\mathrm{CaCl}_{2} 250 \mathrm{mg} / \mathrm{L}$, and $\mathrm{GA} 0.5 \mathrm{mmol} / \mathrm{L}$.
\end{abstract}

\section{Introduction}

The pitaya is kind of vine cactus, which is one of the typical tropical famous fruits. It is also known as the red dragon fruit and cactus fruit [1]. Pitaya fruit is rich in nutrients, anthocyanins and plant albumin, vitamins and water-soluble dietary fiber, which are rare in plants. It has many functions such as cancer prevention, anti-oxidation and immunity enhancement. But the cold resistance of pitaya is poor. Temperature is the main limiting factor for the development of pitaya fruit production. It is suitable for pitaya to grow in an environment with an average annual temperature of 18.5 degrees Celsius. When the temperature is lower than 5 degrees Celsius, the pitaya plant will be frozen, and its young buds, shoots and even some mature branches will suffer frozen damage. Improving the cold resistance of pitaya plants can provide theoretical reference for expanding the planting area of pitaya in practical production.

2,4-epibrassinosteroids (BR) is a kind of brassinosteroids, which participates in the regulation of plant growth and development in many aspects, and has good effects in improving plant stress resistance, promoting seed germination, seedling growth and antioxidant enzyme activity [3]. Glycine betaine (GB) is a tetramine compound which is easily absorbed and utilized by plant tissues. As an osmotic regulator, it participates in the osmotic regulation of plant cells, improves the stability of the structure and function of biological macromolecules, and ultimately improves the adaptability of plants to low temperature stress conditions [4]. Previous study showed that the effect of $7.5 \mathrm{mM} \mathrm{GB}$ on improving cold resistance of banana Seedling leaves under low temperature stress was the best [5]. Calcium is closely related to the transmission of low temperature information. $\mathrm{Ca}^{2+}$ is a major second messenger [6], which participates in plant response and adaptation to low temperature stress by regulating gene expression related to cold injury. Previous study also showed that $1400 \mathrm{mg} / \mathrm{L}$ calcium chloride treatment could alleviate the effect of low temperature on tomato leaves [7]. Salicylic acid (SA) is a plant hormone widely existing in plants. SA is involved in the regulation of plant growth and development. SA is also an important signal molecule in response to adversity. Many studies have shown that, SA can improve plant cold resistance by increasing antioxidant enzyme activity, reducing electrolyte exosmosis and alleviating the decrease of MDA content.

\section{Materials and Methods}

\subsection{Materials}

The pitaya plants were purchased from the Pitaya base in Jinqiao Town, Shuangliu District, Chengdu City. The variety is 'Taiwan N0. 6'. Fresh annual pitaya plants with similar maturity, uniform size and no pests and diseases were selected as experimental materials. 


\subsection{Experimental Design}

L9 $\left(3^{4}\right)$ orthogonal experiment design was used. Four factors and three concentration levels were used. Spraying clean water at low temperature was used as control (CK), as shown in Tables 1 and 2.

Table 1. Test factors and levels

\begin{tabular}{ccccc}
\hline \multirow{2}{*}{ level } & $\mathrm{A}$ & $\mathrm{B}$ & $\mathrm{C}$ & $\mathrm{D}$ \\
& 2,4-epibrassinolide $(\mu \mathrm{g} / \mathrm{L})$ & Betaine $(\mathrm{mmol} / \mathrm{L})$ & $\mathrm{CaCl}_{2}(\mathrm{mg} / \mathrm{L})$ & salicylic $(\mathrm{mmol} / \mathrm{L})$ \\
\hline 1 & 1 & 2.5 & 250 & 0.5 \\
2 & 10 & 5 & 500 & 1 \\
3 & 100 & 10 & 750 & 1.5 \\
\hline
\end{tabular}

Table 2. Orthogonal experimental design

\begin{tabular}{ccccc}
\hline \multirow{2}{*}{ Test number } & \multicolumn{3}{c}{ Factor } & D \\
\cline { 2 - 5 } & A & B & C & 1 \\
T1 & 1 & 1 & 1 & 2 \\
T2 & 1 & 2 & 2 & 3 \\
T3 & 1 & 3 & 3 & 3 \\
T4 & 2 & 1 & 2 & 1 \\
T5 & 2 & 3 & 2 \\
T6 & 2 & 3 & 1 & 2 \\
T7 & 3 & 1 & 3 & 3 \\
T8 & 3 & 2 & 1 & 1 \\
T9 & 3 & 3 & 2 & \\
\hline
\end{tabular}

The above-mentioned solutions were sprayed evenly on the surface of pitaya branches in a spray pot until dripping water on the surface. After drying, they were sprayed for the second time and for the third time. After drying, all the sprayed branches were placed in a refrigerator at $0 \pm 1{ }^{\circ} \mathrm{C}$ for low temperature stress treatment. Sampling was carried out on the 7th day of treatment for each index detection.

\subsection{Indicators and Methods for Determination}

Relative electrical conductivity (REC) was determined by the method of Deng [8]. The contents of soluble sugar, soluble protein, free proline (Pro) and malondialdehyde (MDA) were determined by anthracene colorimetry, coomassie brilliant blue staining, acid ninhydrin colorimetry and thiobarbituric acid (TBA) colorimetry, respectively. The chilling injury index of pitaya was classified according to the study of Gao [10].

\subsection{Data Statistics and Analysis}

The experiments data were analyzed by Excel 2010 and DPS 7.05 software, and the significant difference $(P<$ $0.05)$ was compared by LSD test.

\section{Results and Analysis}

\subsection{Effects of Different Treatments on Chilling Injury Index of Pitaya Branches}

As shown in Fig. 1, except for T7 and T8, all the other treatments can improve the cold resistance of Pitaya to a certain extent, but the effects are different. The treatment of T2, T4 and T5 had the most obvious effect, and the chilling injury index decreased by $20 \%$ compared with the control, while the treatment of $\mathrm{T} 1$ and $\mathrm{T} 6 \mathrm{had}$ the lowest chilling injury index by $6.66 \%$ and $13.33 \%$ compared with the $\mathrm{CK}$, respectively.

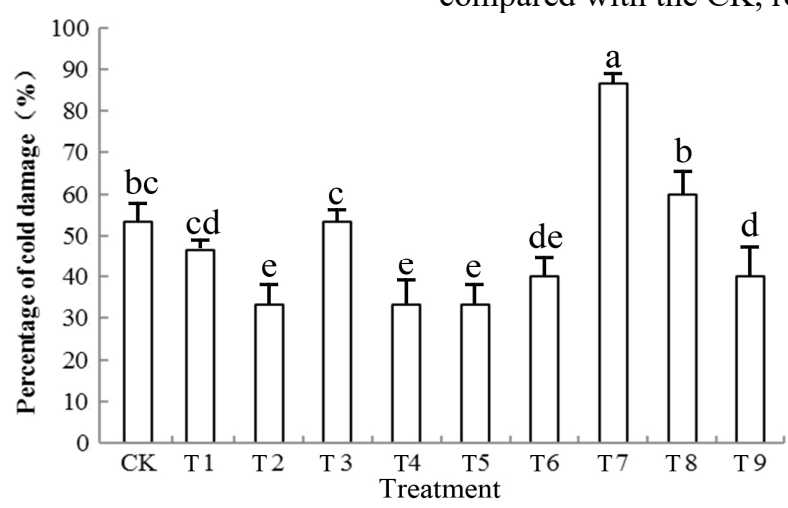

Fig. 1. Effects of different treatments on chilling injury index of Pitaya branches

Note: Different letters in each column indicate significant differences $(P<0.05)$ among different treatments, the same below. 


\subsection{Effects of Different Treatments on Cell Membrane Stability of Pitaya Branches}

The stability of cell membrane can be reflected by relative conductivity and malondialdehyde content. Different treatments had greatly different influence on the REC of pitaya branch cells. The REC of T2, T6 and T7 treatments was more than $60 \%$ compare to CK (Table 3), while that of $\mathrm{T} 1$ treatment and $\mathrm{CK}$ treatment was the lowest $(41.43 \%$ and $48.43 \%$, respectively), and the difference was significant. The REC of other treatments ranged from $55 \%$ to $60 \%$, but the difference was not significant. The effects of different treatments on MDA content in pitaya branches were also different. More than half of the treatments had MDA content above 20 $\mu \mathrm{mol} \cdot \mathrm{g}^{-1}$, but the MDA content of T4 and T5 treatments was lower than $20 \mu \mathrm{mol} \cdot \mathrm{g}^{-1}$, significantly lower than that in other treatments.

These results indicated that the cell membrane stability of pitaya branches were affected by exogenous chemicals which may be potential cold resistance regulator.
Table 3. Effects of Different Treatments on REC and MDA Content of Pitaya Branches

\begin{tabular}{ccc}
\hline Treatment & REC $(\%)$ & MDA $\left(\mu \mathrm{mol} \cdot \mathrm{g}^{-1}\right)$ \\
\hline CK & $48.73 \pm 1.97 \mathrm{~b}$ & $44.64 \pm 6.29 \mathrm{a}$ \\
T1 & $41.43 \pm 13.06 \mathrm{c}$ & $30.84 \pm 8.29 \mathrm{c}$ \\
T2 & $61.18 \pm 3.63 \mathrm{a}$ & $21.77 \pm 3.59 \mathrm{~d}$ \\
T3 & $55.10 \pm 9.85 \mathrm{a}$ & $21.63 \pm 6.18 \mathrm{~d}$ \\
T4 & $55.76 \pm 5.95 \mathrm{a}$ & $18.93 \pm 2.23 \mathrm{de}$ \\
T5 & $56.81 \pm 8.88 \mathrm{a}$ & $11.44 \pm 7.46 \mathrm{e}$ \\
T6 & $60.74 \pm 4.40 \mathrm{a}$ & $46.78 \pm 3.10 \mathrm{a}$ \\
T7 & $64.23 \pm 6.60 \mathrm{a}$ & $42.67 \pm 3.65 \mathrm{ab}$ \\
T8 & $58.08 \pm 4.33 \mathrm{a}$ & $40.04 \pm 4.03 \mathrm{ab}$ \\
T9 & $56.23 \pm 4.82 \mathrm{a}$ & $37.45 \pm 7.65 \mathrm{bc}$ \\
\hline
\end{tabular}

\subsection{Effects of Different Treatments on Osmotic Adjustment Substances in Pitaya Branches}

The osmotic adjustment substances of plant cells are mainly soluble sugar, soluble protein and proline. Table 4 showed that the soluble sugar content of $\mathrm{T} 3$ and $\mathrm{T} 8$ treatments was the highest above all the treatments, reaching $1.06 \%$ and $0.97 \%$ respectively, while that of T5 was the lowest, reaching $0.28 \%$. The soluble protein and proline content of $\mathrm{T} 1$ treatment were the highest, and significantly higher than most other treatments, of which soluble protein was $126 \%$ higher than $\mathrm{CK}$ and proline was $350 \%$ higher than CK.

Table 4. Effects of different treatments on contents of soluble sugar, soluble protein and proline of pitaya branches

\begin{tabular}{cccc}
\hline Treatment & Soluble sugar $(\%)$ & Soluble protein $\left(\mu \mathrm{g} \cdot \mathrm{g}^{-1}\right)$ & Free proline $\left(\mu \mathrm{g} \cdot \mathrm{g}^{-1}\right)$ \\
\hline CK & $0.58 \pm 0.03 \mathrm{bcd}$ & $34.18 \pm 8.84 \mathrm{de}$ & $46.50 \pm 0.96 \mathrm{e}$ \\
T1 & $0.43 \pm 0.01 \mathrm{~cd}$ & $77.03 \pm 5.62 \mathrm{a}$ & $207.15 \pm 22.99 \mathrm{a}$ \\
T2 & $0.67 \pm 0.03 \mathrm{abcd}$ & $56.36 \pm 7.81 \mathrm{bc}$ & $109.39 \pm 19.62 \mathrm{bcd}$ \\
T3 & $1.06 \pm 0.03 \mathrm{a}$ & $70.83 \pm 13.85 \mathrm{ab}$ & $151.25 \pm 38.82 \mathrm{~b}$ \\
T4 & $0.82 \pm 0.03 \mathrm{abc}$ & $36.30 \pm 3.94 \mathrm{de}$ & $113.31 \pm 37.29 \mathrm{bcd}$ \\
T5 & $0.28 \pm 0.01 \mathrm{~d}$ & $42.99 \pm 10.82 \mathrm{~cd}$ & $150.76 \pm 16.37 \mathrm{~b}$ \\
T6 & $0.51 \pm 0.01 \mathrm{bcd}$ & $21.48 \pm 2.34 \mathrm{ef}$ & $83.45 \pm 5.94 \mathrm{~cd}$ \\
T7 & $0.69 \pm 0.03 \mathrm{abcd}$ & $43.94 \pm 7.22 \mathrm{~cd}$ & $73.27 \pm 11.55 \mathrm{~d}$ \\
T8 & $0.97 \pm 0.05 \mathrm{ab}$ & $69.92 \pm 13.16 \mathrm{ab}$ & $122.15 \pm 25.37 \mathrm{bc}$ \\
T9 & $0.50 \pm 0.02 \mathrm{~cd}$ & $17.64 \pm 4.25 \mathrm{f}$ & $85.21 \pm 1.94 \mathrm{~cd}$ \\
\hline
\end{tabular}

In the orthogonal compound factor experiment, D factor had the greatest influence on the cold resistance of pitaya plant, B factor had the smallest influence, A factor and $\mathrm{C}$ factor were between them. Salicylic acid plays a significant role in improving plant cold resistance. Previous Study showed that salicylic acid treatment was better than $\mathrm{CaCl}_{2}$. The effect of $1 \mathrm{mmol} / \mathrm{L}$ sodium salicylate solution on improving leaf cold resistance of Machilus chinensis seedlings is the best, which was consistent with the results of this experiment. The mechanism of salicylic acid improving plant cold resistance may be that salicylic acid can increase the content of hydrogen peroxide in plants by binding with salicylic acid binding protein, further activate the activity of antioxidant enzymes, thereby improving plant stress resistance.

\section{Conclusion}

According to multiple comparisons, A1B1C1D1 was the best treatment to improve the cold resistance of pitaya branches. BRs concentration was $0.001 \mathrm{mg} / \mathrm{L}$, GB concentration was $2.5 \mathrm{mmol} / \mathrm{L}, \mathrm{CaCl}_{2}$ concentration was $250 \mathrm{mg} / \mathrm{L}$ and GA concentration was $0.5 \mathrm{mmol} / \mathrm{L}$.

\section{References}

1. L. Yunna, Nor. Horticul., 14, 204-205, (2018).

2. R. J. Deng, J. X. Fan, Y. Q. Wang, Chin. J. Trop. 
Crops, 39, 260-266, (2018).

3. H. P. Yan, Y. L. Pan, X. Q. Zhang, Acta Agric. Nucl. Sin, 30, 988-996, (2016).

4. S. J. Liang, A. Q. Luo, M. Han, Nor. Horticul., 22, 57-61, (2018).

5. W. Liu, L. B. Xu, Y. Q. Chen, Nor. Horticul., 7, 22-25, (2012).

6. X. M. Wang, H. Rong, Y. Q. Li, South China Fruits. 44, 45-47, (2015).

7. M. S. Jahan, Y. Wang, S. Shu, Sci. hortic-Amsterdam, 247, 421-429, (2019).

8. Z. Y. Li, S. C. Zeng. Physiol. plant resistance, China Agri. Press, Beijing, 46-51, (1994).

9. Q. Y. Xu. Experimental Course of Plant Physiol. Sichuan Sci. Techn. Press, Chengdu, 66-78, (2003).

10. G. L. Guo, B. X. Zhong, G. Qiu, J. Huazhong Agric. Univ, 33, 26-32, (2014). 